\title{
Drinking and thinking: alcohol and health
}

I remember being struck some years ago during a presentation on fluoride by the lecturer responding to a question about safety by saying that everything was a poison if you took it in sufficient quantity. So, if you consumed fluoride, albeit without really being aware of it, in tea or water then it was unlikely to be a problem, whereas if you ate mouthfuls of it in concentrated chemical form you would almost certainly suffer ill effects.

I have been reminded of this scale of effect versus consumption as we have been putting together this issue of the journal, since it includes two papers and two news items on the subject of alcohol. The reason is of course immediately apparent, the more alcohol you drink the greater the effect.

As a society we have a strange relationship with alcohol. On the one hand it is unquestionably a drug, a mind-altering substance to use the modern and slightly euphemistic parlance. On the other hand, for many of us, it is an essential and deeply ingrained part of our social fabric. With the obvious exception of those groups, religious and others who do not consume alcohol, how many of us would even think of inviting friends to dinner, celebrating almost any occasion where adults are involved and certainly throwing a party without alcohol being part of the equation?

However, none of us can be unaware of the health implications, damage, injury and devastation that can be caused by the consumption of alcohol in excess, whether in the short term form of drunkenness and binge drinking or the longer term consequences of habituation and addiction. Just as with poisons, it is a matter of balance - how much do you take before it becomes a problem? And there's the rub. As we know from our daily work in all aspects of human biology and health there are no absolute measures. What is a safe quantity for one person is a disaster for another. It comes down to judgement, where it automatically also becomes a much more difficult matter to deal with.

The impact of alcohol is a cause for reflection for us on three levels; socially in our attitude to it, professionally in the way in which our own, our colleagues' and team members' use of it may affect our ability as health care providers, and the way in which our patients' use of it affects their general and oral health. Curiously, when you stop to think about it, alcohol has a much greater impact on our lives than we realise. It can be a truly insidious influence; a good servant but a bad master.

The two alcohol related papers in this issue touch on exactly these points. Dental students are known for their tendency to drink heavily, or binge drink, and we doubtless have similar memories from our own students days (does our jolly laugher at the memories make it socially acceptable?) and the paper by Barber et al. (p. 581) compares this to law students as a similar social group, reporting that if anything our legal colleagues have an even worse record - how many of our patients are lawyers?

The other paper by Dempster et al. (p. 587) focuses on our patients and reminds us that one impact of drunkenness, literally and metaphorically, is oral and facial trauma. The authors' approach to try and prevent this provides interesting reading and illustrates how as a profession we need to find new and inventive ways of tackling alcohol related ill health. Young men are at particular risk of this type of injury but we also have to remember on the eve of Mouth Cancer Awareness Week that alcohol has serious health implications for patients at the other end of the age spectrum too. Insidious indeed.

As a profession we are clearly not alone in this. The news media has been full recently of items on binge drinking. There has been a call by the Health Secretary for the Chancellor to "really increase" taxes on drinks like alcopops to prevent the situation where hospitals were "filling up" with youngsters at weekends. The EU Health Commissioner has pledged to do more to curb binge drinking throughout Europe, where it is estimated that some 55 million adults (one in eight of the population) are drinking dangerous amounts of alcohol.

So what can we do? Should we encourage companies and organisations who sponsor dental student functions to place caveats that their funding must not be used for alcohol purchase? Should we press for the legal age of drinking to be raised to 21? Should we look at our own 'social' consumption before we start looking to curb that of others? Or should we fundamentally rethink our attitude to the substance and the increasing effect it is having on our social fabric and our nation's health?

There is no one answer because there is no one question. It is a problem as complex as the reasons for which each of us chose to drink the amount of alcohol we do. One thing we can all do though is to consider more carefully how we regard it, how we use it and the attitude we take to it in relation to both our patients' and our own health.

Stephen Hancocks OBE, Editor-in-Chief

If you have, or a colleague that you know of has, a problem with alcohol use or with the use and abuse of any other drug or substance the Dentists Health Support Programme is available to help. The telephone number is 01327262823 and the Programme prides itself on its complete confidentiality. Established for many years the Programme has provided help, support and rehabilitation to many colleagues and has a remarkable success rate. It is run by dentists, for dentists and the telephone number is included in the contents pages of every issue of the BDJ.

doi: $10.1038 / s j . b d j .4814233$ 